\title{
AS ESPÉCIES DE LUDWIGIA L. (ONAGRACEAE) NO CÓRREGO SÃO JOSÉ EM TANGARA DA SERRA-MT
}

Adelair Mendes Conceição ${ }^{1}$, Rozineide Pereira Alves de França ${ }^{2}$, Débora Vieira de Araújo $^{2}$. Mara Silvia Aguiar $\mathrm{Abdo}^{3}$.

${ }^{1}$ Graduada em Ciências Biológicas, Universidade do Estado de Mato Grosso,

Tangará da Serra-MT, Brasil. adelairmendes@hotmail.com

${ }^{2}$ Graduada em Ciências Biológicas, Universidade do Estado de Mato Grosso, Tangará da Serra-MT, Brasil.

${ }^{3}$ Docente do curso de Ciências Biológica da Universidade do Estado de Mato Grosso (UNEMAT), Tangará da Serra-MT, Brasil.

Recebido em: 08/04/2016 - Aprovado em: 30/05/2016 - Publicado em: 20/06/2016 DOI: 10.18677/Enciclopedia_Biosfera_2016_120

\begin{abstract}
A família Onagraceae possui cerca de 650 espécies distribuídas nas regiões subtropicais e temperadas. O gênero Ludwigia ocorre em todo o Brasil, estando associado a regiões alagadas, entretanto há uma baixa densidade de estudo sobre as espécies do gênero Ludwigia para o Estado de Mato Grosso. O Córrego São José, localizado no município de Tangará da Serra, apresenta as margens degradadas pela ação do uso na agropecuária e piscicultura. Desta forma há falta de conhecimento da vegetação natural. $O$ presente estudo tem como objetivo caracterizar as espécies de Ludwigia L. presente em quatro represas do Córrego São José. As coletas foram realizadas em agosto de 2014 e março de 2015. As amostras foram coletadas aleatoriamente ao entorno das represas, e herborizadas e identificadas. $O$ resultado deste trabalho foi o registro de três espécies de Ludwigia: Ludwigia nervosa, L. elegans e L. tomentosa. A Ludwigia nervosa apresentou a maior abundancia (14 indivíduos) e ocorreu nas quatro represas. Enquanto as outras duas espécies, $L$. elegans e $L$. tomentosa apresentaram três indivíduos cada. A primeira apareceu nas represas 1 e 3 e a segunda apareceu nas represas 2,3 e 4.
\end{abstract}

RESUMO

PALAVRAS- CHAVE: corpos d"água, Macrófitas, plantas aquáticas.

\section{SPECIES OF LUDWIGIA L. (ONAGRACEAE) IN THE STREAM SÃO JOSÉ IN TANGARA DA SERRA-MT}

\begin{abstract}
The family Onagraceae has around 650 espécies distribuídas nas regiões subtropicais e temperadas. The type Ludwigia takes place in all Brazil, being associated to flooded regions, meantime there is a low study density on the sorts of the type Ludwigia for the State of Mato Grosso. The Stream Saint José located in the local authority of Tangará of the Mountain range, he presents the edges degraded by the action of the use in the farming and fish farming. In this way there is lack of knowledge of the natural vegetation. The present study has as I aim to characterize
\end{abstract}


the sorts of Ludwigia L. present in four dams of the Stream Saint José. The collections were carried out in August of 2014 and March of 2015. The samples were collected aleatoriamente to an entorno of the dams, and botanized and identified. The result of this work was the register of three sorts of Ludwigia: Ludwigia Nervous L. elegans and L. tomentose. The nervous Ludwigia presented the biggest abundancia (14 individuals) and took place in four dams. While others two sorts, L. elegans and $L$. tomentose three individuals presented each. The first one appeared in the dams 1 and 3 and on Monday appeared in the dams 2,3 and 4.

KEYWORDS: Macrophyte, plants aquatic, bodies d'água.

\section{INTRODUÇÃO}

A família Onagraceae possui cerca de 650 espécies distribuídas nas regiões subtropicais e temperadas (SALOMON \& DIETRICH, 1984). RAMAMORTHY \& ZARDINI (1987) citaram Ludwigia L. como um dos maiores e mais diversos gêneros de Onagraceae, com 82 espécies, das quais 45 ocorrem na América do Sul, distribuídas em 23 seções.

Segundo SOUZA \& LORENZI (2012), o gênero Ludwigia ocorre em todo o Brasil, estando associado a regiões alagadas. Assim, podendo ser denominados de macrófitas aquáticas. As macrófitas aquáticas são em sua grande maioria, vegetais terrestres que ao longo de seu processo evolutivo, se readaptaram ao ambiente aquático, por isso apresentam algumas características de vegetais terrestres e uma grande capacidade de adaptação a diferentes tipos de ambientes (POTT \& POTT, 2000).

Macrófitas aquáticas é a denominação mais adequada para caracterizar vegetais que habitam desde brejos até ambientes verdadeiramente aquáticos, incluindo macroalgas, uma denominação genérica, independente dos aspectos taxonômicos (ESTEVES, 2011). POTT \& POTT (2000) consideram aquáticas as plantas cuja parte fotossinteticamente ativa estão permanentemente ou por alguns meses submersos ou flutuantes.

POTT \& POTT (2000) registraram 16 espécies de Ludwigia para o Pantanal Mato Grossense. A forma de vida encontrada destas plantas é a maioria terrestre anfíbia e duas espécies do tipo fixam flutuante. Entretanto, há uma baixa densidade de estudo sobre as espécies do gênero Ludwigia para o Estado de Mato Grosso.

Mato Grosso, hoje é o estado que apresenta o maior crescimento na área do agronegócio. Assim, as extensas áreas são desmatadas sem ainda ter-se o conhecimento da diversidade vegetal e animal. $\mathrm{E}$ o mais grave, as regiões de drenagens como: córregos, pequenos rios e lagoas, com vegetação natural estão cada vez mais reduzidas. São esses locais que apresentam as margens degradadas pela ação do uso na agropecuária extensiva utilizada no estado, e em menor escala a piscicultura. Nestas condições encontra-se o Córrego São José no município de Tangará da Serra. Desta forma, o objetivo deste estudo foi identificar as espécies de Ludwigia L. presente em quatro represas no córrego São José, em Tangará da Serra.

\section{MATERIAL E MÉTODOS}

O presente estudo foi realizado no município de Tangará da Serra, localizado na mesorregião sudoeste do estado de Mato Grosso, na Serra Tapirapuã a 421 metros de altitude. As coletas foram realizadas no córrego São José, que faz parte da bacia do rio Sepotuba. Este córrego localiza-se na área rural, desta forma, suas 
margens se apresentam desflorestadas para dar lugar a pastagem, além, da construção de várias represas, para a dessedentação do gado e piscicultura. Um trecho deste córrego fica próximo a Universidade do Estado de Mato Grosso, Campus de Tangará da Serra- MT (Figura 1). Para este estudo foram escolhidas quatro represas (Figura 1) ao longo do córrego São José. As coletas das plantas foram realizadas em agosto de 2014 e março de 2015, de forma aleatória no entorno das represas.

As plantas coletadas férteis foram acondicionadas em sacos plásticos e levadas para o laboratório de Botânica. Estas foram prensadas e secas em estufas e posteriormente identificadas utilizando as bibliografias especializadas. Posteriormente as exsicatas foram doadas para a coleção do Herbário TANGUnemat/Tangará da Serra.

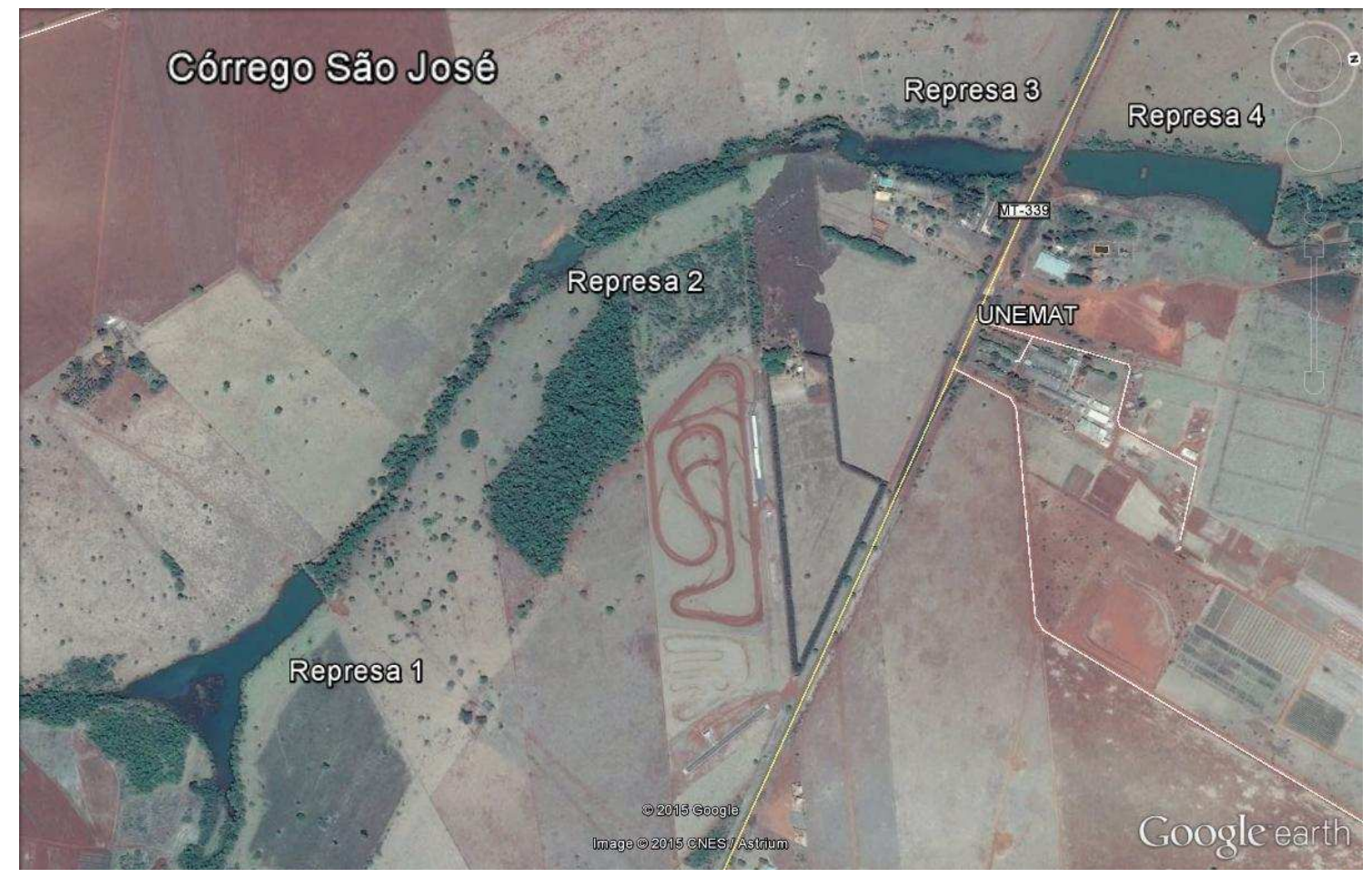

FIGURA 1: Imagem do córrego São José e das quatro represas estudadas, na proximidade da Universidade do Estado de Mato Grosso, Brasil. Fonte: Google Earth 2013.

\section{RESULTADOS E DISCUSSÃO}

O córrego São José é um córrego de pequeno porte, com largura média de dois metros, com águas claras e velocidades que variam de acordo com o relevo do terreno, ocorrendo pequenas quedas d'água com cerca de 1,5 metros. Nas represas a água perde a velocidade e formam grandes espelhos d'água e com profundidades maiores que dois a três metros. Ao longo do córrego e no interior das represas ocorre a presença da palmeira Buriti (Mauritia flexuosa L.f.). Estas formam as vezes pequenas ilhas na represa, dando lugar a outras espécies de plantas. 
As quatro represas apresentam margens bastante degradadas pela ação da atividade agropecuária. Entre uma represa e outra o córrego apresenta timidamente a vegetação arbórea natural, pouco conservada. Nas margens das represas desmatadas, além da pastagem pode se notar a presença de outras espécies de plantas pertencentes às famílias : Poaceae, Cyperaceae, solanaceae, Acerácea, Lytraceae, Moraceae entre outras. Neste conjunto foram Encontradas Ludwigia elegans (Cambess.) H.Hara, Ludwigia nervosa (Poir.) H.Hara e Ludwigia tomentosa (Cambess.) H.Hara.

\section{Ludwigia elegans (Cambess.) H.Hara}

Ervas a arbusto palustre até $2 \mathrm{~cm}$, decumbente a ereto, ramos geralmente glabros, os mais jovens pilosos. Folha alterna, peciolada, com estipulas inconspícuas, glabras, lâmina lanceolada, a oval, até $15 \mathrm{~cm}$, margens levemente crenadas ou sinuosas, glândulas diminutas na face inferior, nervuras secundarias 20-30. Flores bissexuadas, sépalas 4, deltóides, livres, pétalas 4, livres, amarelas, precocemente caducas, estames 8, ovário ínfero,4-locular, cilíndrico, com disco nectaríferos piloso, estilete 1. Fruto cápsula, glabro. Planta nativa da América do sul, considerada infestante no Brasil. Florence no outono e inverno.

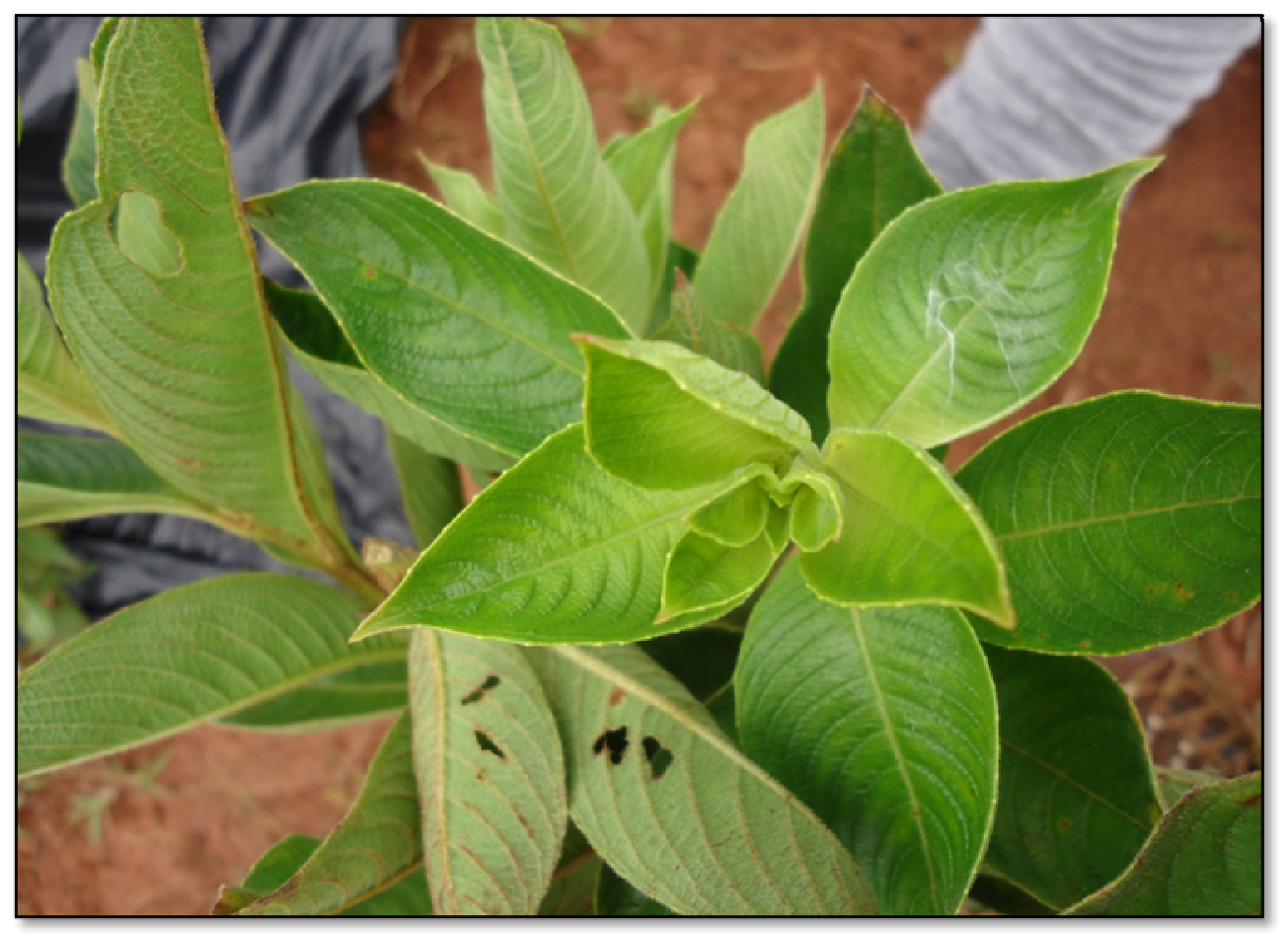

FIGURA 2: Foto parcial de um indivíduo de Ludwigia elegans, na represa 1, do córrego São José, Tangará da Serra, MT.

\section{Ludwigia nervosa (Poir.) H.Hara.}

Arbusto arborescente palustre, até seis metros, ereto, bastante modificado, pubescente. Folha alterna, séssil ou com pecíolo curtíssimo, com estipulas inconspícuo, glabro a pilosas, lâmina lanceolada a elíptica, até $13 \mathrm{~cm}$. Margem 
ligeiramente glandulosa, levemente crenada, nervuras secundarias 6-12. Flores bissexuadas, terminais e axilares, solitárias, pedicelo até $1 \mathrm{~cm}$, sépalas 4 , livres, pelos na face inferior, pétalas 4 livres, amarelas, estames 8, amarelos, ovário ínfero, 4-locular, cilíndrico, alas com cílios, disco nectarífero piloso, estilete 1. Fruto cápsula. Distribuição neotropical. Floresce praticamente o ano todo.

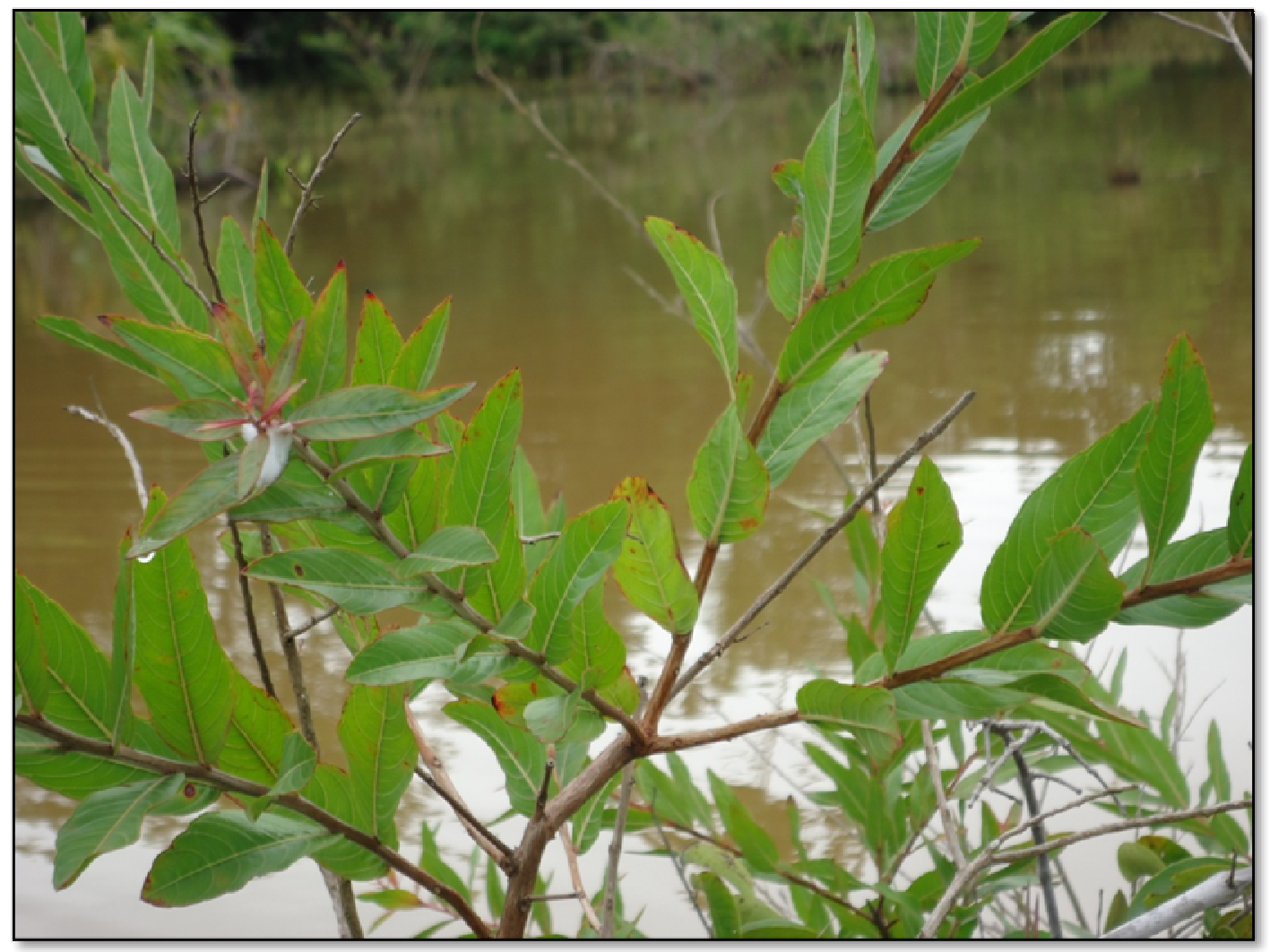

FIGURA 3: Foto parcial de um indivíduo de Ludwigia nervosa, na represa 2, do córrego São José, Tangará da serra, MT.

\section{Ludwigia tomentosa (Cambess.) H.Hara.}

Arbusto palustre até 1,5 metro, ereto, ramificado na base, ramos pilosos. Folhas alternas, subsésseis, com estipulas inconspícuas, lamina elíptica, até $8 \mathrm{~cm}$, pilosa em ambas as faces, mais intensamente na face interior, nervuras secundarias11-12. Flores bissexuadas solitárias, pediceladas, sépalas 4, esverdeadas, livres, pilosas, pétalas 4, amarelas, livres, glabras, estames 8, amarelos, estigma, amarelo, ovário ínfero,4- locular, cônico, disco nectarífero piloso, estilete 1. Fruto cápsula. Ocorrência na argentina, Uruguai, Bolívia e no Brasil, da região sudeste até na Bahia; é considerado daninha. Floresce no verão e inverno. 


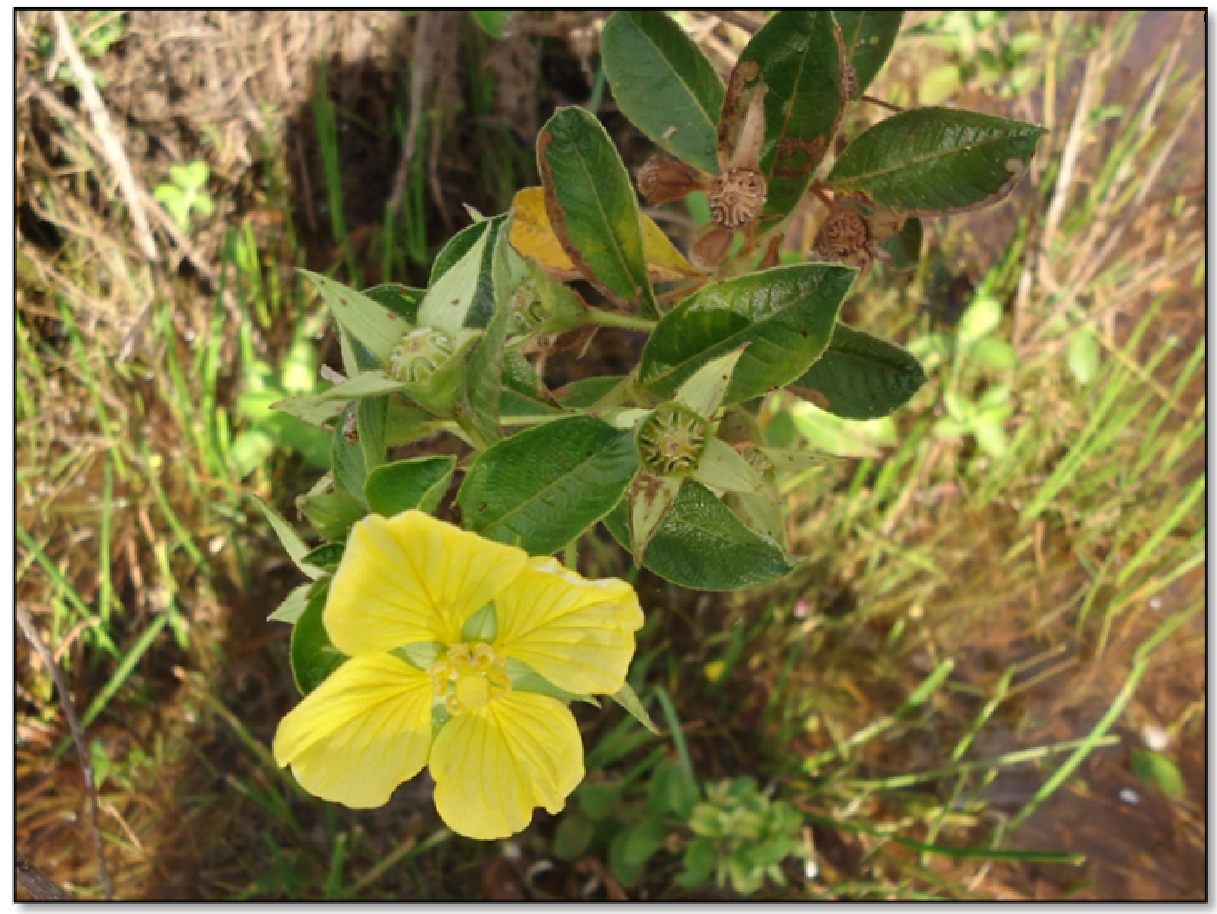

FIGURA 4: Foto parcial de um indivíduo de Ludwigia tomentosa florida, na represa 3, no córrego São José, Tangará da Serra, MT.

Muitos indivíduos de Ludwigia foram encontrados na faixa litorânea da represa (Figura 5) formando pequenos aglomerados. Outros foram encontrados em solo umedecido a seco. No período de estiagem foi possível encontrar uma maior quantidade de indivíduos na fase fértil Ludwigia nervosa foi a espécie com maior abundancia (14 indivíduos) e ocorreu nas quatro represas. Enquanto que L. elegans e $L$. tomentosa apresentaram três indivíduos cada. A primeira apareceu nas represas 1 e 3 e a segunda apareceu nas represas 2,3 e 4.

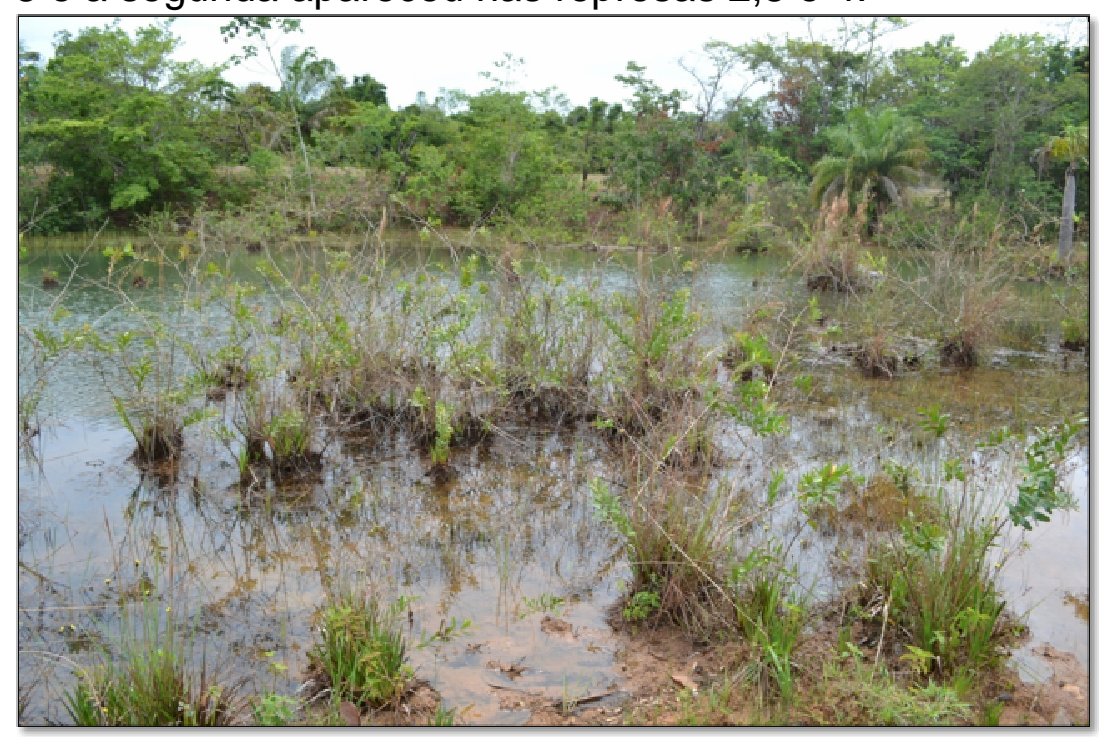

FIGURA 5: Foto parcial da Represa 2, com a formação de pequenas ilhas com tufos de plantas com a Ludwigia e cercada por espécies de Cyperaceae, Xyridaceae e outras.Córrego São José, Tangará da Serra, MT. 
A Lista de Espécie da Flora Brasileira é um banco de dados, onde estão inseridas todas as espécies coletadas e depositadas nos herbários do Brasil. A partir destes dados, verificar-se os registros das espécies coletadas neste estudo. $\mathrm{Na}$ tabela 1, está a relação de espécies estudadas e as registradas em outros locais do Brasil. Ludwigia nervosa e L.elegans são as mais encontradas em todos os biomas do Brasil. E L. tomentosa se apresenta restrita aos biomas Cerrado e Caatinga.

TABELA 1: Domínios fitogeográficos das espécies coletadas nas quatro represas do Córrego São Jose.

\begin{tabular}{|l|c|c|c|c|c|c|}
\hline \multicolumn{1}{|c|}{ Espécies } & Amazônia & Caatinga & Cerrado & $\begin{array}{c}\text { Mata } \\
\text { Atlântica }\end{array}$ & Pampa & Pantanal \\
\hline Ludwigia nervosa & $\mathbf{X}$ & $\mathbf{X}$ & $\mathbf{X}$ & $\mathbf{X}$ & $\mathbf{X}$ & $\mathbf{X}$ \\
\hline Ludwigia tomentosa & & $\mathbf{X}$ & $\mathbf{X}$ & & & \\
\hline Ludwigia elegans & $\mathbf{X}$ & $\mathbf{X}$ & $\mathbf{X}$ & $\mathbf{X}$ & & $\mathbf{X}$ \\
\hline
\end{tabular}

Dentre as pesquisas realizadas no Brasil, com a abordagem de inventários de macrófitas aquáticas na região do Pantanal (POMPÊO et al., 2015; PIVARI et al., 2011; CUNHA et al, 2012; POTT \& POTT 2000), em área úmida do Cerrado (MUNHOZ \& FELFILI, 2012; SOUSA,2014) a Ludwigia nervosa, foi mais frequente. Enquanto que a Ludwigia tomentosa foi encontrada em trabalhos realizados em áreas úmidas do bioma Cerrado (MUNHOZ \& FELFILI, 2012; BUENO et al., 2014, SOUSA,2014). Já Ludwigia elegans encontra-se em trabalhos relacionados com interação com abelhas (GIMENEZ, 2002; MOUGA \& KRUG, 2010).

\section{CONCLUSÃO}

Nas quatro represas do córrego São José foram identificadas Ludwgias nervosa, Ludwigia elegans e Ludwigia tomentosa. Sendo que Ludwgias nervosa foi encontrada com maior abundâcia. Assim, ressalta-se a importância de mais estudos da florística desta região, pois, é uma área que sofre intensa degradação devido aos empreendimentos na área da agricultura e pecuária extensiva, e piscicultura.

\section{REFERENCIAS}

BERTUZZI,T.; G, D. ; SCOTTI, T.C.D.; EISINGER, S. M. O gênero Ludwigia L. (Onagraceae) no município de Santa Maria, Rio Grande do Sul, Brasil. Ciência e Natura, UFSM, 33 (1): 43 - 73, 2011.

BUENO, ML.; DAMASCENO-JUNIOR, GA.; POTT, A.; PONTARA, V.; SELEME, EP.; FAVA, WS.; SALOMÃO, AKD.; RATTER, JA. Structure of arboreal and herbaceous strata in a neotropical seasonally flooded monodominant savanna of Tabebuia áurea.

Braz. J. Biol. vol. 74, no. 2, p. 325-33,2014.

CUNHA, NL. DELATORRE, M., RODRIGUES, RB., VIDOTTO, C., GONÇALVES, F. ,SCREMIN-DIAS, E., DAMASCENO-J, G. , POTT, VJ. POTT, A. Estrutura da vegetação aquática em uma grande lagoa, borda oeste do Pantanal brasileiro. Braz. J. Biol. [online]. vol.72, n.3, pp. 519-531, 2012.http://dx.doi.org/10.1590/S151969842012000300015.

ESTEVES, F.A. Fundamentos de Limnologia. 3rd ed. Editora Interciência, Rio de Janeiro, 826p, 2011. 
GIMENEZ, M .Interactions between bees and Ludwigia elegans (Camb.) Hara (Onagraceae) flowers at different altitudes in Sao Paulo, Brazil Revta bras. Zool. 19 (3): 681 - 689, 2002

MOUGA, D. M.D.S. E KRUG, C. Comunidade de abelhas nativas (Apidae) em Floresta Ombrófila Densa Montana em Santa Catarina. ZOOLOGIA 27 (1): 70-80, February, 2010.

MUNHOZ, C. B. R.; Vereda: guia de campo. Brasília: Rede de sementes do cerrado p. 224, 2011.

MUNHOZ,C.B.R ;FELFILI, JM - Florística do estrato herbáceo-subarbustivo de um campo limpo úmido em Brasília, Brasil. Biota Neotropica, v7 (n3) - p. 205-215. 2012.

PIVARI, M.O., V.B. OLIVEIRA, F.M. COSTA, R.M. FERREIRA AND A. Salino. Macrófitas aquáticas do sistema lacustre do Vale do Rio Doce, Minas Gerais, Brasil. Rodriguésia 62(4): 759-770, 2011.

POTT, VJ.; POTT, A., LIMA; LCP.; MOREIRA, SN.; OLIVEIRA, AKM. Aquatic macrophyte diversity of the Pantanal wetland and upper basin. Brazilian Journal of Biology . vol.71 no.1 supl. 1 São Carlos, p. 255-263, 2011.

POTT, V. J.; POTT, A. Plantas aquáticas do Pantanal. Brasília: EMBRAPASPI;Corumbá: EMBRAPA-CPAP, 40 p. 2011.

RAMAMOORTHY, T.P.; ZARDINI, E.M. The systematics and evolution of Ludwigia sect. Myrtocarpus s.I. (Onagraceae). Ann.Missouri Bot. Gard. 19:1-120,1987.

RODRIGUES, M E F, MACEDO, C C L; HIRATA, RT E POMPÊO, M. Levantamento Florístico de Macrófitas Aquáticas no Braço Rio Grande, Represa Billings, SP. In Pompêo et al. (Orgs.) Ecologia de reservatórios e interfaces, São Paulo: Instituto de Biociências da Universidade de São Paulo, P.72-81, 2015.

SALOMON, J. C.; DIETRICH, W. Onagráceas. Flora Ilustrada Catarinense. 33p. 1984.

SOUSA, N.L.D; Composição florística de uma área de campo úmido na fazenda pedra vermelha, Analândia. UNESP, São Paulo: Instituto de ciências da universidade de Rio claro, 2014.

SOUZA, L.S.; NUNES, R.O. Levantamento de macrófitas aquáticas no rio Méquens. Facimed, 3: 211-223, 2011.

SOUZA, V.C.; LORENZI, H. 2012. Botânica Sistemática: guia ilustrado para identificação das famílias de Fanerógamas nativas e exóticas no Brasil, baseado em APG III. $3^{\underline{a}}$ ed. Instituto Plantarum, Nova Odessa, São Paulo, 768p, 2012, 